\title{
Locomotor performance of three sympatric species of sea kraits (Laticauda spp.) from Orchid Island, Taiwan
}

\author{
Shiuang Wang ${ }^{1}$, Harvey B Lillywhite ${ }^{2}$ and Ming-Chung Tu*
}

\begin{abstract}
Background: Assuming that locomotion has a strong influence on animals' fitness, we hypothesized that better locomotor performance would be associated with the most frequently utilized habitat. Laticauda colubrina, Laticauda laticaudata, and Laticauda semifasciata have different amphibious habits and microhabitat preferences at Orchid Island, Taiwan. We investigated the morphology and locomotor performance of the three sympatric species of sea krait. The measurements of body size, tail area, and body shape were compared in our study. Data on crawling and swimming speeds were gathered to investigate locomotor performance in terrestrial and aquatic environments.
\end{abstract}

Results: We found significant differences in the locomotor performances among the three species. L. colubrina was the most terrestrial species in habits and sprinted significantly faster than the others during terrestrial locomotion. On the other hand, L. semifasciata was the most aquatic species, and it swam significantly faster than the other two species. These results are consistent with our hypothesis that sea kraits move well in their respective primary environments. With respect to the highly aquatic L. semifasciata, its laterally compressed body form, large body size, and large area of compressed tail are considered to be beneficial to swimming in an aquatic environment.

Conclusions: More data are required to understand the superior terrestrial locomotion of L. colubrina, but this species may benefit from its more-cylindrical body form compared to L. semifasciata and from its greater muscle mass compared to L. laticaudata. L. laticaudata was intermediate in habits but exhibited the poorest performance in both swimming and terrestrial locomotion. The reasons for this remain unclear.

Keywords: Sea krait; Laticauda; Locomotor performance; Morphology; Body shape

\section{Background}

Locomotion is an attribute which has important ecological implications in relation to prey capture, predator avoidance, mate searching, and reproduction. Locomotive performance can improve animals' foraging efficiency (Higham 2007) and the ability to escape predation (Miles 2004; Husak 2006a; Arendt 2009). Resource acquisition can affect animals' energy allocation between growth and reproduction (Bonnet et al. 1998; Kubicka 2009), and predation is also an important selective force shaping morphology, physiology, behavior, and life-history traits in natural populations (Steiner 2007; Hossie et al. 2010). Hence, it is

\footnotetext{
* Correspondence: biofv026@ntnu.edu.tw

${ }^{1}$ Department of Life Science, National Taiwan Normal University, Taipei 116, Taiwan

Full list of author information is available at the end of the article
}

commonly believed that animals' fitness is enhanced with increasing locomotor ability.

Locomotor performance benefits animals in various ways. Garter snakes Thamnophis sirtalis fitchi that have greater speed and endurance are more likely to survive (Jayne and Bennett 1990). A high correlation between locomotor performance and survival was also found in lizards (Husak 2006b). In the collared lizard Crotaphytus collaris, a strong correlation between a male's sprint speed and territory size indicates that faster males might have better opportunities to mate (Peterson and Husak 2006). Additionally, a higher sprint speed also helps male collared lizards in reproduction (Husak et al. 2006) and survival (Peterson and Husak 2006).

Locomotor systems are generally designed to function well in circumstances where they are usually employed 
(Losos 1990; Aubret and Shine 2008a). The evolutionary transition from terrestrial to aquatic habitats caused subsequent modifications in morphology, physiology, and behavior, especially when strong selective pressures are exerted by aquatic habitats. For example, aquatic snakes that move forward by accelerating portions of the surrounding water (Shine et al. 2003) have a laterally compressed body form, a shorter tail, a higher tail height, and a larger tail area (Brischoux and Shine 2011) compared to terrestrial snakes. These character states presumably increase the lateral surface area devoted to thrust and thereby enhance a snake's swimming performance (Pattishall and Cundall 2008). In contrast, friction is responsible for generating propulsive forces in terrestrial locomotion. Reactive forces are formed when lateral undulatory locomotors push against irregularities in the substrate. Once the forces are sufficiently great to overcome sliding frictional resistance, the animal moves (Gans 1974). A snake's terrestrial locomotor speed is affected by frictional differences among substrates (Scribner and Weatherhead 1995) and also varies with the substrate area with which the snake's body is in contact (Finkler and Claussen 1999). For amphibious species such as sea kraits, it is important to crawl and swim well due to requirements of foraging in the ocean and returning to land for mating, oviposition, digestion, and skin sloughing (Heatwole 1999). However, animals face different challenges when moving in different media. While aquatic locomotor performance is improved by a sea krait's laterally flattened body shape, this body form leads to a decrease in the substrate area contacted with the ventral portion of the body, thus impairing terrestrial locomotion. In addition, comparisons conducted between aquatic and terrestrial snakes also revealed a habitatdependent difference in muscle structures (Jayne 1982).

Three laticaudine sea kraits are distributed in coastal waters around Orchid Island (Lanyu in Chinese), Taiwan. Although they occur sympatrically on reef areas during the nighttime, subtle differences in microhabitat utilization can still be found among them. Laticauda semifasciata can be seen submerging in the water or retreating very close to the water. Laticauda laticaudata retreats to reef areas not far from the water, whereas Laticauda colubrina behaves like a terrestrial snake and crawls away from the water to shrubby vegetation that occurs along the coast (Liu, unpublished data). Other studies similarly indicated that $L$. colubrina is the most terrestrial of the three species, L. semifasciata is the most aquatic, and L. laticaudata is intermediate in amphibious habits (Bonnet et al. 2005; Lillywhite et al. 2009).

Due to these differences in terrestrial tendencies, we predicted that a better crawling ability and a superior swimming performance should respectively characterize L. colubrina and $L$. semifasciata. Moreover, the locomotor performance of $L$. laticaudata should be intermediate both on land and in the water. We also tested the hypothesis that in these sea kraits, the extent of lateral body compression and the surface area of the paddle-shaped tail should be consistently linked to differences in aquatic vs. terrestrial tendencies, such that values of body height/width ratio and the tail surface area should rank from high to low in L. semifasciata, L. laticaudata, and L. colubrina.

\section{Methods}

\section{Animal collection and housing}

This study was conducted in 2008 and 2009. Sexual size dimorphism was found in L. colubrina and L. semifasciata (Shetty and Shine 2002; Shine et al. 2002; Cox et al. 2007), and sexual differences in body shape have strong influences on both terrestrial (Bonnet et al. 2005) and aquatic (Brischoux et al. 2010) locomotion. Hence, we collected only adult male snakes for our investigation on locomotor performance of these sea kraits.

Females were also excluded from our study to avoid the potential effect of gravidity and due to their limited appearance at our sites. Males were collected by hand on Orchid Island $\left(22^{\circ} 03^{\prime} \mathrm{N}, 121^{\circ} 32^{\prime} \mathrm{E}\right)$, which is a $45-\mathrm{km}^{2}$ island situated $60 \mathrm{~km}$ off the southeastern coast of Taiwan. All the animals collected for our study were treated in accordance with the protocol approved by The Animal Care and Use Committee of National Taiwan Normal University (permit \#93013). All snakes were maintained in damp cloth bags and were transported to National Taiwan Normal University, Taipei within 5 days. Each snake was individually housed in a plastic container (length $\times$ width $\times$ height of $27 \times 24 \times 16 \mathrm{~cm}$ ) filled $3 \mathrm{~cm}$ deep with fresh water. The snakes were fasted and placed in a room that was kept at a constant $25^{\circ} \mathrm{C}$ with a photoperiod of $12 \mathrm{~h}$ dark/12 $\mathrm{h}$ light. They were housed for 1 day before we tested their performance in locomotion. After the testing was completed, all snakes were released at the same site where they were collected.

\section{Morphology}

In total, 117 individuals (32 L. colubrina, 48 L. laticaudata, and $37 \mathrm{~L}$. semifasciata) were collected for the locomotor performance tests. We recorded the snout-vent length (SVL), tail length, and mass of each snake. The tail area was recorded in all but 34 individuals that were used in other projects. The lateral surface area of the tail was measured by converting the relative weight proportion of the tail shape delineated on A4-sized paper. All measurements were used in the correlation analyses between morphology and locomotor performance in the three sea snake species.

Additional sea kraits (17 L. colubrina, 16 L. laticaudata, and $16 \mathrm{~L}$. semifasciata) were collected to measure the body shape, which is more laterally compressed during 
swimming than when in a resting state. The roundness index (body height/body width) used in previous research (Pattishall and Cundall 2008) was adopted as a body shape index. To standardize measurements along the body length, we marked the trunk sequentially at one fourth, one half, and three fourth of the SVL from the tip of the snout with white paint. We then compared the index among body segments and species. The laterally compressed body form of sea kraits is more obvious when they are swimming and when they are being caught. They continued moving when they were caught and held in the air, and their bodies were laterally compressed as when they were swimming. Thus, data of body shape in a laterally compressed state was measured immediately when they were caught and trying to get away. The resting status of the body was only achieved after being placed in a cage with no disturbance. In both circumstances, we measured the body height and width using electronic digital calipers (to a precision of $0.01 \mathrm{~mm}$; Mitutoyo CD-15 DC, Mitutoyo Ltd., Tokyo, Japan). These measurements were taken at three segments of the body during resting and moving states. The ratio of the roundness index during resting and moving states was calculated as 'ratio change index' to investigate the extent of body shape change between states.

\section{Locomotor performance}

An acrylic racetrack $(3.0 \mathrm{~m}$ long, $0.5 \mathrm{~m}$ wide, and $0.5 \mathrm{~m}$ deep) was used for the locomotion tests. Every $25 \mathrm{~cm}$, a black line was marked at the bottom of the racetrack. A camera (30 fps, VG4C-XP-V, Chateau Technical Corp., Taipei, Taiwan) with a digital timer was suspended above each line, except for the first one. In total, ten cameras were used to record the time when a snake passed each black line. To examine whether the grain of the substrate affected the crawling speed, three types of substrate (shingle, coral, and fine gravel) were used in preliminary tests to determine the optimal substrate for maximum crawling speeds which could be achieved during the test. The average particle sizes of these substrates were 66.0 (shingle), 13.0 (coral), and $2.5 \mathrm{~mm}$ (fine gravel) in diameter. Even though L. laticaudata showed no difference in crawling speeds on the various substrates, a significantly higher speed on the fine gravel surface was found in L. colubrina (analysis of variance (ANOVA) $F_{2,27}$ $=7.02, p=0.0035$; Tukey's test, $p<0.05)$ and $L$. semifasciata $\left(F_{2,51}=11.73, p<0.0001\right.$; Tukey's test, $\left.p<0.05\right)$. Thus, the fine gravel was chosen as the substrate for subsequent trials on terrestrial locomotion. To measure swimming speeds, artificial seawater $(34.74 \mathrm{~g} / \mathrm{kg}$; Coralife Scientific Grade Marine Salt, Energy Savers Unlimited, Carson, CA, USA) was filled inside the racetrack to a depth of $15 \mathrm{~cm}$. About one half of the snakes were first tested in aquatic trials, and the others were first tested in terrestrial trials. Snakes were tested in random order during the daytime, and all snakes completed one aquatic trial and one terrestrial trial. Both trials were done on two consecutive days with a 24-h interval between trials. Each snake was released at one end of the racetrack to begin the trial. Snakes began subsurface swimming immediately after release in the aquatic trials, but they were encouraged to move down the racetrack by light taps on the tail during terrestrial trials. We stopped the test when we found that a snake had stopped moving or began moving in the opposite direction. In such cases, we repeated the test after waiting at least $1 \mathrm{~h}$.

Van Damme and Van Doren (1999) suggested that relative speed (body length/s) was a better predictor of escaping predation than was the absolute speed $(\mathrm{m} / \mathrm{s})$. But Shine et al. (2003) also proposed that too little is known about the relative significance of the two types of measures in laticaudine locomotion. Thus, we included both measures of speed in this study. The sprint and average speeds were adopted as indices of locomotor performance. For each snake, the sprint speed was the fastest speed calculated in any $0.25-\mathrm{m}$ interval of the racetrack, whereas the average speed was the mean speed measured after completion of the trial.

\section{Data analyses}

We performed a one-way ANOVA to compare body lengths (SVLs) among the sea kraits, and a one-way analysis of covariance (ANCOVA) with SVL as the covariate was conducted for interspecific comparisons of tail length, tail area, and body mass. For each species of sea krait, roundness indices measured separately in either the resting or moving state of the three body segments (anterior, middle, and posterior) were compared with a one-way ANOVA. Body shape differences among the sea kraits were separately analyzed in the resting and moving states using a repeated-measures ANOVA with roundness indices measured in the three body segments (anterior, middle, and posterior) as the repeated measure and species as the factor. Sea kraits changed their body shape between the resting and moving states. By dividing the roundness indices of different states (resting state/compressed state), a ratio change index was created to represent the extent of body shape change between states. We ran a repeated-measures ANOVA with ratio change indices calculated for the three body segments as the repeated measures and species as the factor to compare interspecific differences in the extent of body shape changes between the resting and moving states. Locomotor performances on land and in water were separately compared with a one-way ANOVA with species as the factor and speed (absolute and SVL/s) as the dependent variable. When the ANOVA or ANCOVA results were statistically significant, Tukey's test was used for post hoc pair-wise comparisons at $\alpha=0.05$. Multiple regressions were run to assess the effects of morphological 
variables (SVL, body mass, tail length, and tail area) on the locomotor performance. Because SVL, body mass, tail length, and tail area were highly correlated, we calculated regressions using residuals of the body mass, tail length, and tail area regressed on the SVL. All analyses were performed with JMP 7.0 (SAS Institute, Cary, NC, USA) statistical software.

\section{Results}

\section{Morphology}

The SVLs of the three sea kraits significantly differed from each other (ANOVA, $F_{2,114}=28.13, p<0.0001$; Tukey's test, $p<0.05$; Table 1 ). ANCOVAs with SVL as the covariate demonstrated a significant species effect on tail length $\left(F_{2,113}=9.77, p<0.0001\right.$; Table 1$)$, tail area $\left(F_{2,113}=157.23, p<0.0001\right)$, and body mass $\left(F_{2,113}=208.57, p<0.0001\right)$ among the sea krait species. Subsequent Tukey's tests showed that tail lengths in L. semifasciata and L. colubrina did not statistically differ, but the tail of L. laticaudata was significantly shorter than the others $(p<0.05$; Table 1$)$. The body mass and tail area of the three species significantly differed from each other, with the rank order from highest to lowest values being $L$. semifasciata, L. colubrina, and $L$. laticaudata (Tukey's test, $p<0.05$ ).

Data on the body roundness index of the three sea kraits measured at the anterior, middle, and posterior segments of their bodies are given in Table 2. In a resting state, intraspecific comparisons revealed no differences among body segments in the roundness index (ANOVAs, $p>0.05$ ). In interspecific comparisons, the repeated-measures ANOVA revealed a significant species effect on the body shape during a resting state $\left(F_{2,96}=5.33, p=0.0083\right)$. A subsequent Tukey's test showed that $L$. laticaudata had a significantly higher roundness index than that of $L$. semifasciata $(p<0.05)$, and $L$. colubrina had a median value of the index that did not statistically differ from the others. In a moving state, ANOVAs of the body roundness index revealed a significant body shape difference among the three segments in L. colubrina $\left(F_{2,48}=14.16, p<0.0001\right)$, L. laticaudata $\left(F_{2,45}=18.27, p<0.0001\right)$, and $L$. semifasciata $\left(F_{2,45}=\right.$ $7.29, p=0.001)$. A significantly higher roundness index was found in the posterior segment of all the sea kraits $(p<0.05$, Tukey's test; Table 2). An interspecific comparison showed that the body shapes of the three sea kraits significantly differed from each other (repeated-measures ANOVA, $F_{2,96}=55.62, p<0.0001$; Tukey's test, $p<0.05$ ). L. semifasciata had the highest body roundness index, and L. colubrina had the lowest value. When the ratio change index was used to represent the extent of the body shape change between states, $L$. semifasciata was also found to have a significantly higher extent of body shape change from a resting to a moving state than did the others (repeated-measures ANOVA with ratio change indices in the three body segments as the repeated measure and species as the factor; $F_{2,96}=29.35, p<0.0001$; Tukey's test, $p<0.05$ ).

\section{Locomotor performance}

Separate one-way ANOVAs on locomotor performance revealed significant interspecific differences in both the relative sprint crawling speed $\left(F_{2,114}=8.81, p<0.0001\right.$; Figure 1$)$ and relative sprint swimming speed $\left(F_{2,114}=\right.$ $11.20, p<0.0001)$. The interspecific difference in locomotor performance was still significant in crawling (ANOVA, $F_{2,114}=6.51, p<0.0001$; Figure 1 ) and swimming (ANOVA, $F_{2,114}=23.01, p<0.0001$ ) when the average speed was used as the index. L. colubrina was found to have a higher crawling speed, and L. semifasciata was found to have a higher swimming speed; L. laticaudata was the slowest species during both terrestrial and aquatic trials. Subsequent multiple comparisons showed a significant interspecific difference in the locomotor performance among the sea kraits $(p<0.05$, Tukey's test; Figure 1). L. colubrina sprinted significantly faster than the others. L. semifasciata had higher swimming speeds, but they did not significantly differ from those of $L$. colubrina. L. laticaudata was the slowest sea krait during crawling and swimming.

When using the measure of absolute speed $(\mathrm{m} / \mathrm{s})$ as the predictor, the ANOVAs demonstrated significant interspecific differences in sprint crawling speed $\left(F_{2,114}=6.54\right.$, $p=0.002$; Figure 2), sprint swimming speed $\left(F_{2,114}=21.46\right.$, $p<0.0001)$, average crawling speed $\left(F_{2,114}=4.79, p<0.01\right)$, and average swimming speed $\left(F_{2,114}=38.14, p<0.0001\right)$. Although absolute speeds revealed similar patterns to relative speeds presented in the analyses, $L$. semifasciata

Table 1 Snout-vent length, body mass, tail length, and tail area of sea kraits measured for the locomotor performance test

\begin{tabular}{|c|c|c|c|c|c|c|}
\hline & \multicolumn{2}{|c|}{ L. colubrina } & \multicolumn{2}{|c|}{ L. laticaudata } & \multicolumn{2}{|c|}{ L. semifasciata } \\
\hline & Mean (SE) & Range & Mean (SE) & Range & Mean (SE) & Range \\
\hline Snout-vent length $(\mathrm{cm})$ & $79.2(1.3)$ & 65.5 to $94.5(\mathrm{C})$ & $82.5(0.8)$ & 65.5 to $94.0(B)$ & $85.5(0.9)$ & 79.2 to $101.5(\mathrm{~A})$ \\
\hline Body mass (g) & $188.3(10.4)$ & 103.3 to $352.5(b)$ & $167.3(5.6)$ & 75.1 to 273.1 (b) & $484.2(13.4)$ & 339.1 to 618.6 (a) \\
\hline Tail length (cm) & $12.1(0.2)$ & 10.0 to $15.1(B)$ & $11.8(0.2)$ & 8.1 to $18.7(B)$ & $13.5(0.2)$ & 11.6 to $16.0(A)$ \\
\hline Tail area $\left(\mathrm{cm}^{2}\right)$ & $18.1(0.7)$ & 12.8 to $23.8(b)$ & $17.5(0.6)$ & 10.9 to $23.2(b)$ & $32.4(0.5)$ & 24.5 to $43.7(a)$ \\
\hline
\end{tabular}

Different letters in parentheses indicate a significant interspecific difference in values of a morphological variable (Tukey's test, $a=0.05$ ). 
Table 2 Body roundness index (body height/width) of three sea kraits measured in the anterior, middle, and posterior regions of their bodies

\begin{tabular}{|c|c|c|c|c|c|c|c|}
\hline \multirow[b]{2}{*}{ Species } & \multirow[b]{2}{*}{ Number } & \multicolumn{3}{|c|}{ Resting state } & \multicolumn{3}{|c|}{ Moving state } \\
\hline & & Anterior & Middle & Posterior & Anterior & Middle & Posterior \\
\hline L. colubrina & 17 & $0.92 \pm 0.02(-)$ & $0.90 \pm 0.02(-)$ & $0.94 \pm 0.03(-)$ & $1.14 \pm 0.02(\mathrm{~B})$ & $1.24 \pm 0.03(\mathrm{~A})$ & $1.29 \pm 0.03(\mathrm{~A})$ \\
\hline L. laticaudata & 16 & $0.96 \pm 0.02(-)$ & $0.97 \pm 0.02(-)$ & $1.01 \pm 0.03(-)$ & $1.23 \pm 0.02(b)$ & $1.25 \pm 0.03(b)$ & $1.40 \pm 0.03$ (a) \\
\hline L. semifasciata & 16 & $0.89 \pm 0.02(-)$ & $0.86 \pm 0.02(-)$ & $0.92 \pm 0.03(-)$ & $1.38 \pm 0.02(B)$ & $1.38 \pm 0.03(B)$ & $1.55 \pm 0.03(A)$ \\
\hline
\end{tabular}

Data of different states are presented separately as the mean \pm SE. Different letters in parentheses indicate a significant intraspecific difference in values (Tukey's test, $a=0.05)$.

was found to have significantly higher speeds for both the sprint swimming speed and average swimming speed than the other species $(p<0.05$, Tukey's test).

For each species, results of the multiple regression analyses indicated that overall morphological variables (SVL, residuals of body mass, tail length, and tail area) did not significantly predict locomotor performance of the three sea kraits, but the residual tail area by itself was identified as a significant predictor of swimming speeds in L. colubrina (absolute sprint speed and absolute average speed, Table 3 ).

\section{Discussion}

Our data demonstrated that there are interspecific differences in locomotor performance among these three sea krait species, and these results support our principal hypothesis. Being the most terrestrial species of the three sea kraits, L. colubrina demonstrated the fastest sprint speed during the terrestrial locomotion test. On the other hand, L. semifasciata is a more highly aquatic species and performed significantly better in the water, having the highest sprint swimming speed. These data suggest that

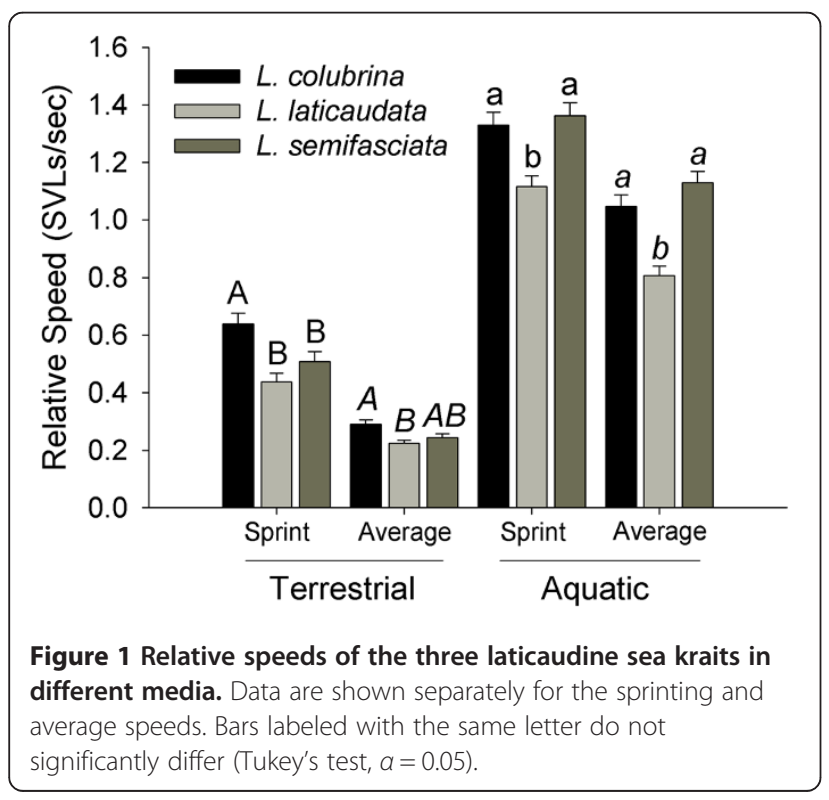

sea kraits have adaptive locomotor capabilities that have evolved to improve performance in their respective principal habitat.

Morphological characters can greatly influence the locomotor capabilities of animals. In snakes, including sea kraits and other sea snake species, swimming speed increases with an increasing size of individuals (Jayne 1985, Shine and Shetty 2001, Shine et al. 2003). Studies of common garter snakes also revealed that a higher maximum crawling speed is associated with an increasing body mass (Heckrotte 1967). However, our results revealed that only the residual tail area of L. colubrina was correlated with the absolute sprint and absolute average speeds in the multiple regression models. Sea kraits investigated by Shine et al. (2003) had large ranges of body sizes (35 to $131 \mathrm{~cm}$ in L. colubrina and 41 to $115 \mathrm{~cm}$ in L. laticaudata). The adult sea kraits collected in our study had comparatively narrower ranges of body sizes (65.5 to $94.5 \mathrm{~cm}$ in L. colubrina, 65.5 to $94.0 \mathrm{~cm}$ in L. laticaudata, and 79.2 to $101.5 \mathrm{~cm}$ in L. semifasciata). Within the rather narrow ranges of body sizes studied, and maybe also because the sample size was

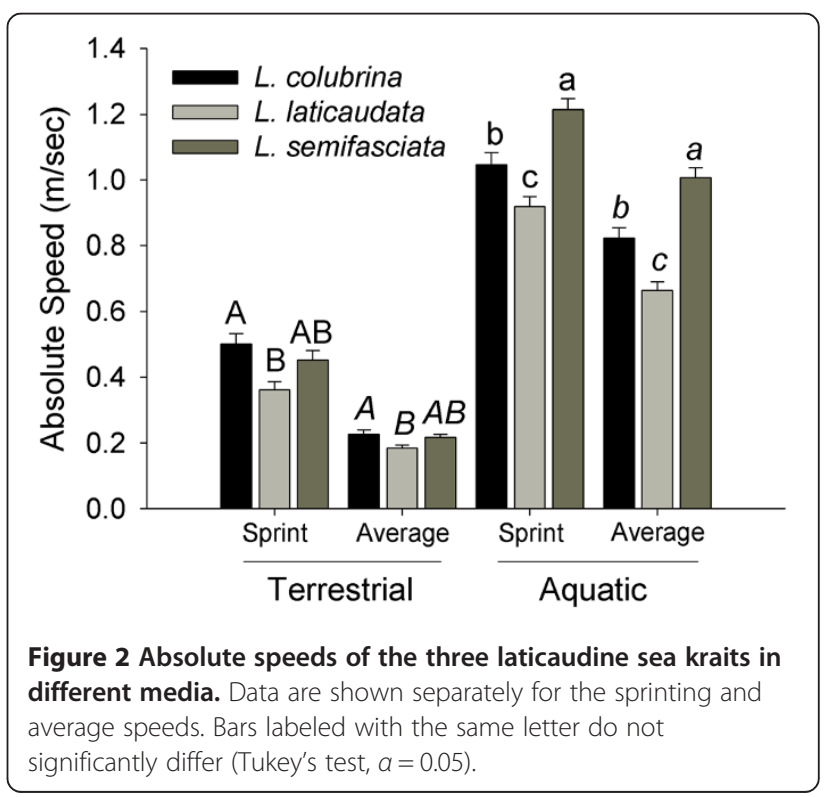


Table 3 Estimates for the associations between morphological variables and sea krait locomotor performance in the regression models

\begin{tabular}{|c|c|c|c|c|c|c|}
\hline & \multicolumn{3}{|c|}{ Absolute sprint swimming ${ }^{a}$} & \multicolumn{3}{|c|}{ Absolute average swimming ${ }^{b}$} \\
\hline & $b \pm \mathrm{SE}$ & $t$ & $p$ & $b \pm S E$ & $t$ & $p$ \\
\hline Snout-vent length & $0.00 \pm 0.01$ & 0.04 & NS & $0.00 \pm 0.01$ & -0.12 & NS \\
\hline Residual tail length & $-0.11 \pm 0.08$ & -1.38 & NS & $-0.13 \pm 0.07$ & -1.73 & NS \\
\hline Residual weight & $0.00 \pm 0.00$ & -1.54 & NS & $0.00 \pm 0.00$ & -1.57 & NS \\
\hline Residual tail area & $0.07 \pm 0.03$ & 2.19 & 0.04 & $0.07 \pm 0.03$ & 2.33 & 0.03 \\
\hline
\end{tabular}

${ }^{\mathrm{a}} n=22, R^{2}=0.35, R_{\mathrm{adj}}^{2}=0.195, F_{4,17}=2.26, p=0.11 .{ }^{\mathrm{b}} n=22, R^{2}=0.26, R_{\text {adj }}^{2}=0.08, F_{4,17}=1.46, p=0.26$.

not big enough, significant correlations between morphological variables and locomotor performance could not be detected in our study. Swimming speeds (0.35 to 2.04 $\mathrm{SVL} / \mathrm{s}$ and 23 to $141 \mathrm{~cm} / \mathrm{s})$ and crawling speeds $(0.02$ to $0.63 \mathrm{SVL} / \mathrm{s}$ and 2 to $46 \mathrm{~cm} / \mathrm{s}$ ) in other species of sea snakes were reported by Shine et al. (2003); measurements of swimming speeds that we obtained for sea kraits were lower but still within those ranges. Terrestrial speeds that we measured were generally slower than the speeds (1.29 SVL/s and 31.23 to $91.7 \mathrm{~cm} / \mathrm{s}$ ) measured in various terrestrial species of snakes such as Notechis scutatus (Aubret et al. 2007) and T. s. fitchi (Jayne and Bennett 1989, 1990), but comparisons are dependent on the mode of locomotion. Crawling speeds of sea kraits were nearly an order of magnitude lower than maximum speeds $(5 \mathrm{~m} / \mathrm{s})$ recorded for rapidly moving terrestrial snakes such as mambas (Goldman and $\mathrm{Hu} 2010$ ).

Morphological modifications are frequently found in organisms that adapt to specific environments. With respect to aquatic environments, both a paddle-shaped tail and a laterally compressed body form can produce greater propulsive forces compared to what a cylindrical body offers in undulatory swimming animals (Lighthill 1975; Gillis 1996; Aubret and Shine 2008b; Brischoux and Shine 2011; Sanders et al. 2012). The positive correlation between swimming speed and the extent of lateral body compression in Nerodia sipedon suggests that the temporarily flattened body promotes swimming performance in that species (Pattishall and Cundall 2008). A flattened paddle-like tail also appears to provide a major reason why sea kraits swim more rapidly than do their terrestrial counterparts (Shine and Shetty 2001). In our study, the two sea krait species exhibited obvious lateral compression of their posterior body when moving. In addition, L. semifasciata had the most compressed body form when moving, and it also had a significantly larger tail area than did the other sea kraits. These features characteristic of $L$. semifasciata appear to explain its superior swimming capability compared to the other two species.

Although we expected L. laticaudata to have a median locomotor performance in crawling and swimming due to its intermediate level of terrestriality among the three sea kraits, the slow locomotion of L. laticaudata in both media did not conform to our hypothesis. An intermediate morphology might not always produce an intermediate performance. On the contrary, it might produce the worst performance. For example, metamorphosing tadpoles are most vulnerable to predators during the developmental transition (with legs and a tail) due to their worst escape performance (Wassersug and Sperry 1977; Crump 1984). Similarly, in horned beetles, intermediate morphologies are rare or absent from natural populations due to their inferior competition for mating (Madewell and Moczek 2006). When an intermediate morphology produces an inferior performance and inferior fitness, it may result in disruptive selection, a well-known selection mode in nature.

In addition, animals may have different tactics in response to predation and foraging; thus, L. laticaudata may have other behavioral adaptations to cope with ecological requirements of its microhabitat. Moreover, aquatic emydid turtle species have higher speeds in both aquatic and terrestrial locomotion, whereas terrestrial and semiterrestrial species tend to have slower speeds but greater endurance in both aquatic and terrestrial environments (Stephens and Wiens 2008). The slowest locomotor speed of L. laticaudata when both crawling and swimming may be explained from a perspective of the trade-off between locomotor ability and other functional attributes.

\section{Conclusions}

Differences in locomotor performance between $L$. semifasciata and L. colubrina support the prediction of their adaptation to particular microhabitats and can be explained as a consequence of sea kraits utilizing microhabitats where they experience a better 'fit'. The excellent swimming capability of L. semifasciata may be explained by its highly lateral compressed body form during a moving state. However, the observation that L. laticaudata moves most slowly among the three species of sea kraits remains enigmatic and invites further detailed research concerning behavior and habitat utilization by these species. 


\section{Competing interests}

The authors have no competing interests to declare.

\section{Authors' contribution}

SW proposed the idea, carried out the literature review, designed the study, performed data collection, statistical analysis, and drafted this manuscript. $\mathrm{HBL}$ assisted with critical revision of the manuscript. M-CT participated in the design of the study and writing the manuscript. All authors read and approved the final manuscript.

\section{Acknowledgements}

We are greatly indebted to $\mathrm{N}$. Chou for providing field research facilities during the study period. We are grateful to Y. Hsu for her valuable advice on conducting statistical analyses. We express our appreciation to K. Lai for his help with designing the racetrack and also to Y. C. Cheng, C.-J. Chang, C. Huang, and Y.-L. Liu for their assistance with fieldwork. This research was funded by the National Science Council of Taiwan (NSC97-2621-B-003-004-MY3). Funding for HBL was from a National Science Foundation grant (IOS-0926802) during production of the manuscript.

\section{Author details}

${ }^{1}$ Department of Life Science, National Taiwan Normal University, Taipei 116, Taiwan. ${ }^{2}$ Department of Biology, University of Florida, Gainesville, FL 32611 , USA.

Received: 23 January 2013 Accepted: 14 May 2013

Published: 15 November 2013

\section{References}

Arendt JD (2009) Influence of sprint speed and body size on predator avoidance in New Mexican spadefoot toads (Spea multiplicata). Oecologia 159:455-461

Aubret F, Shine R (2008a) Early experience influences both habitat choice and locomotor performance in tiger snakes. Am Nat 171:524-531

Aubret F, Shine R (2008b) The origin of evolutionary innovations: locomotor consequences of tail shape in aquatic snakes. Funct Ecol 22:317-322

Aubret F, Bonnet X, Shine R (2007) The role of adaptive plasticity in a major evolutionary transition: early aquatic experience affects locomotor performance of terrestrial snakes. Funct Ecol 21:1154-1161

Bonnet X, Bradshaw D, Shine R (1998) Capital versus income breeding: an ectothermic perspective. Oikos 83:333-342

Bonnet X, Ineich I, Shine R (2005) Terrestrial locomotion in sea snakes: the effects of sex and species on cliff-climbing ability in sea kraits (Serpentes, Elapidae, Laticauda). Biol J Linn Soc 85:433-441

Brischoux F, Kato A, Ropert-Coudert Y, Shine R (2010) Swimming speed variation in amphibious seasnakes (Laticaudinae): A search for underlying mechanisms. J Exp Mar Biol Ecol 394:116-122

Brischoux F, Shine R (2011) Morphological adaptations to marine life in snakes. J Morphol 272:566-572

Cox RM, Butler MA, John-Alder HB (2007) The evolution of sexual size dimorphism in reptiles. In: Fairbairn DJ, Blanckenhorn WU, Szekely T (eds) Sex, size and gender roles: evolutionary studies of sexual size dimorphism. Oxford Univ. Press, London, pp 38-49

Crump ML (1984) Ontogenetic changes in vulnerability to predation in tadpoles of Hyla pseudopuma. Herpetologica 40:265-271

Finkler MS, Claussen DL (1999) Influence of temperature, body size, and inter-individual variation on forced and voluntary swimming and crawling speeds in Nerodia sipedon and Regina septemvittata. J Herpetol 33:62-71

Gans C (1974) Biomechanics an approach to vertebrate biology. Univ. of Michigan Press, Ann Arbor, Ml

Gillis GB (1996) Undulatory locomotion in elongate aquatic vertebrates: anguilliform swimming since Sir James Gray. Am Zool 36:656-665

Goldman D, Hu D (2010) Wiggling through the world. Am Sci 98:314-323 Heatwole H (1999) Sea snakes. Univ. of New South Wales Press, Sydney, Australia Heckrotte C (1967) Relations of body temperature, size, and crawling speed of the common garter snake Thamnophis s. sirtalis. Copeia 1967:759-763

Higham TE (2007) The integration of locomotion and prey capture in vertebrates: morphology, behavior, and performance. Integr Compar Biol 47:82-95

Hossie TJ, Ferland-Raymond B, Burness G, Murray DL (2010) Morphological and behavioural responses of frog tadpoles to perceived predation risk: a possible role for corticosterone mediation? Ecoscience 17:100-108
Husak JF (2006a) Does survival depend on how fast you can run or how fast you do run? Funct Ecol 20:1080-1086

Husak JF (2006b) Does speed help you survive? A test with collared lizards of different ages. Funct Ecol 2006:174-179

Husak JF, Fox SF, Lovern MB, Van Den Bussche RA (2006) Faster lizards sire more offspring: sexual selection on whole-animal performance. Evolution 60:2122-2130

Jayne BC (1982) Comparative morphology of the semispinalis-spinalis muscle of snakes and correlations with locomotion and constriction. J Morphol 172:83-96

Jayne BC (1985) Swimming in constricting (Elaphe g. guttata) and nonconstricting (Nerodia pictiventris) colubrid snakes. Copeia 1985:195-208

Jayne BC, Bennett AF (1989) The effect of tail morphology on locomotor performance of snakes: a comparison of experimental and correlative methods. J Exp Zool 252:126-133

Jayne BC, Bennett AF (1990) Selection on locomotor performance capacity in a natural population of garter snakes. Evolution 44:1204-1229

Kubicka $L$ (2009) First grow, then breed and finally get fat: hierarchical allocation to life-history traits in a lizard with invariant clutch size. Funct Ecol 23:595-601

Lighthill J (1975) Mathematical biofluid dynamics. JW Arrowsmith, Bristol, UK

Lillywhite HB, Menon JG, Menon GK, Sheehy CM III, Tu MC (2009) Water exchange and permeability properties of the skin in three species of amphibious sea snakes (Laticauda spp.). J Exp Biol 212:1921-1929

Losos BJ (1990) The evolution of form and function: morphology and locomotor performance in West Indian Anolis lizards. Evolution 44:1189-1203

Madewell R, Moczek AP (2006) Horn possession reduces maneuverability in the horn-polyphenic beetle, Onthophagus nigriventris. J Insect Sci 6:1-10

Miles DB (2004) The race goes to the swift: fitness consequences of variation in sprint performance in juvenile lizards. Evol Ecol Res 6:63-75

Pattishall A, Cundall D (2008) Dynamic changes in body form during swimming in the water snake Nerodia sipedon. Zoology 111:48-61

Peterson CC, Husak JF (2006) Locomotor performance and sexual selection: individual variation in sprint speed of collared lizards (Crotaphytus collaris). Copeia 2006:216-224

Sanders KL, Rasmussen AR, Elmberg J (2012) Independent innovation in the evolution of paddle-shaped tails in viviparous sea snakes (Elapidae: Hydrophiinae). Integr Compar Biol 52:311-320

Scribner SJ, Weatherhead PJ (1995) Locomotion and antipredator behaviour in three species of semi-aquatic snakes. Can J Zool 73:321-329

Shetty S, Shine R (2002) Sexual divergence in diets and morphology in Fijian sea snakes Laticauda colubrina (Laticaudinae). Aust Ecol 27:77-84

Shine R, Shetty S (2001) Moving in two worlds: aquatic and terrestrial locomotion in sea snakes (Laticauda colubrina, Laticaudidae). J Evol Biol 14:338-346

Shine R, Reed R, Shetty S, Cogger H (2002) Relationships between sexual dimorphism and niche partitioning within a clade of sea-snakes (Laticaudinae). Oecologia 133:45-53

Shine R, Cogger HG, Reed RR, Shetty S, Bonnet X (2003) Aquatic and terrestrial locomotor speeds of amphibious sea-snakes (Serpentes, Laticaudidae). J Zool (Lond) 259:261-268

Steiner UK (2007) Investment in defense and cost of predator-induced defense along a resource gradient. Oecologia 152:201-210

Stephens PR, Wiens JJ (2008) Testing for evolutionary trade-offs in a phylogenetic context: ecological diversification and evolution of locomotor performance in emydid turtles. J Evol Biol 21:77-87

Van Damme R, Van Doren TJM (1999) Absolute versus per unit body length speed of prey as an estimator of vulnerability to predation. Anim Behav 57:347-352

Wassersug RJ, Sperry DG (1977) The relationships of locomotion to differential predation on Pseudacris triseriata (Anura: Hylidae). Ecology 58:830-839

doi:10.1186/1810-522X-52-43

Cite this article as: Wang et al.: Locomotor performance of three

sympatric species of sea kraits (Laticauda spp.) from Orchid Island, Taiwan. Zoological Studies 2013 52:43. 